\title{
Purpose, Composition and Function of the Research Ethical Committee in the Sarah Rehabilitation's Hospital
}

\author{
Kátia Torres Batista ${ }^{*}$, Eliane Maria Fleury Seidl² \\ ${ }^{1}$ Sarah Hospital and University of Brasilia, Brasilia, Brazil \\ ${ }^{2}$ University of Brasilia, Brasilia, Brazil \\ Email: katiatb@terra.com.br, 204265@sarah.br
}

Received 12 January 2016; accepted 17 February 2016; published 22 February 2016

Copyright (C) 2016 by authors and Scientific Research Publishing Inc.

This work is licensed under the Creative Commons Attribution International License (CC BY). http://creativecommons.org/licenses/by/4.0/

(c) (7) Open Access

\section{Abstract}

Introduction: The Research Ethical Committee (REC) is responsible for the ethical evaluation of the projects presented by the scientific community to inform and train the members and researchers. Objective: To describe the purpose, composition and function of the REC of the Association of Social Pioneers (APS) located in the Sarah Rehabilitation's Hospital (Brasilia, Brazil). Methodology: Descriptive analysis of the REC/APS based on 2013's collected data was done. Results: The REC/APS is an independent collegiate body, which was established in 1998 in accordance with Brazilian regulation. The main objective is promoting the application of ethical principles and human rights in research involving humans. The REC was composed by chairperson and a substitute; secretary, fourteen regular members and five substitutes. We analyzed 164 projects submitted. The minimum time to a committee member who came up with the first opinion has been estimated as 14 days and the insurance of the consolidation occurred in 30 days. We approved 64 projects, of which 25 had pendencies in the first analysis, one project failed and 99 were excluded. The main problems were related to the writing of informed consent and the multicenter projects that did not include aspects such as costs, schedule and methodological limitations. We observed that the researcher could provide assistance. We considered the important role of the REC/APS to ensure trust between researchers and participants in the research. Conclusion: Despite the purpose, composition and function of the APS research ethical committee, there were encountered many obstacles in its formation, considering monitoring the progress of the research, national normative, international researches and others. The ethical committee does a vital public service with the variety of the specialized views on the meeting. We need to strike a balance and we must weigh up risks and benefits related to knowledge, in its essence, to research's participant and its relevant social participation.

${ }^{*}$ Corresponding author.

How to cite this paper: Batista, K.T. and Seidl, E.M.F. (2016) Purpose, Composition and Function of the Research Ethical Committee in the Sarah Rehabilitation's Hospital. International Journal of Clinical Medicine, 7, 127-132. 


\section{Keywords}

\section{Ethics Review, Research Ethical Committee, Bioethics and Research}

\section{Introduction}

Patients who participate in research usually give an extraordinary degree of trust in researchers, institutions in which research is conducted, and the research firm as a whole, sometimes the research overlaps the best interests of patients.

Unfortunately, medical research has not always been grounded in the core ethical standards. Our modern ethical standards now have their basis in the Nuremberg Code [1]. These statements were in many documents, including the Declaration of Helsinki [2], Universal Declaration on Bioethics and Human Rights [3], Brazilian Constitution 1988 [4] and other national resolutions. In Brazil, the Research Ethic System is regulated by National Health Council [5]. We have different levels of government-local level (intern regiment), regional level and national level. In 2013, we had six hundred and eighty-four Research Ethical Committees (REC) distributed all over the country. The link used for protocol submission is www.aplicação.saude.gov.br/plataformabrasil/login.jsf [6].

The Research Ethic Committee is part of the Association of Social Pioneers (APS) Institutional Review Board, located in Brasilia, Brazil Federal Capital, designated to protect the rights, safety, dignity and well-being of human subjects and also educate researchers [7].

Association of Social Pioneers (APS) is an interdisciplinary, independent and public Research Ethic Committee in the Sarah Rehabilitation's Hospital. It was established in 1998. It receives protocols of ten public rehabilitation's hospitals in Brazil. These are the APS named Sarah Hospital in nine Brazilian regions. The primary function of the APS/REC is to safeguard human subjects by training researchers in research ethics and the best practices and by reviewing research proposals. The criteria for evaluation are documentation required by the National Regulamentation (466/12 Normative [8]), including cost, schedule, sample, methodology, interest, innovation, relevance and ethics.

Sarah Rehabilitation's Hospital (autonomous social service entity of private law and non-profit) is the name of the network of nine Brazilian hospitals, designed to care for victims of multiple trauma and locomotor problems, aiming to their rehabilitation. It is maintained by the Federal Government, although its management is up to the Association of Social Pioneers.

We are describing the experience and the purpose, composition and function of the REC of the Association of Social Pioneers (APS) based on 2013's data. The study was conducted with 2013's data to analyze the course of resolving the change of the 466/12 Brazilian Ethical Resolution, year of the creation of Resolution 466/12, and know the impact that changes in rules caused to the REC/APS.

\section{Methodology}

The exploratory, descriptive, retrospective study analyzed the records of the REC and of all the 164 research protocols submitted for appreciation from $1^{\text {st }}$ January to $31^{\text {st }}$ December, 2013. We searched the database of the REC/APS in Brazil Platform. It is an electronic system set up by the Federal Government in 2010 to systematize the receipt of research projects involving human beings Ethics Committees throughout the country.

We analyzed all studies that were registered on REC/APS on January up to December 2013. The registered records of these studies were downloaded Research Ethical Committee date in Brazil Platform and analyzed in Microsoft Excel 2007. We did descriptive and frequency analysis of the REC members, studies type and pendencies of the REC/APS based on 2013's data and we described the purpose composition and function.

\section{Results}

In a total of 164 protocols examined on 2013's data, we received 99 incomplete protocols, rejected and 65 were protocols with complete documentation for evaluation according to rules.

The Ethical Committee is composed by chairperson and a substitute, secretary, fourteen regular members and 
five substitutes. The term of the mandate is three years. It is interdisciplinary team composed by seven masters, seven $\mathrm{PhD}$ and two community members. Also, it is composed by an auxiliary Scientific Committee. Our main members (60\%) are doctors and nurses; the others are psychologist, statistic, physiotherapist, professor and sociologist.

In 2013, we had ten meetings, taken monthly, four hours per meeting, where six to eight protocols were studied. The protocols source was Sarah Network. We needed at least nine members to formalize a meeting. The first opinion is due fourteen days, while the last one is due thirty days. We received 164 protocols, 99 rejected due to incomplete documentation, 65 accepted and chosen to be presented on meetings. The Committee members got contact with the protocols before the meetings.

In the meeting, one member introduces each study, and then others give their views. Discussions are well-informed and decisions available to the committee are favorable ethical opinion, favorable with conditions and unfavorable ethical condition. Studies were revised basing on International and National Regulations. The research gathered fifteen thousand and four hundred participants and not a single adverse effect have been reported. The researchers are MSc and PhD Students, clinicians, surgeons and health professionals, including academic researchers (Table 1 ).

It is noteworthy that to evaluate clinical research protocols following documents are required by 466/12 normative: the research project in its completeness, authorization partakers of research (there is a model that permits must be on letterhead of the institution, signed by a responsible institutional member or signature and stamp of the institution responsible), voluntary participation and informed consent, data collection forms, information about the trial, procedures, duration, questionnaires, interviews scripts, cover document generated by Brazil Platform signed by the main researcher, detailed budget, schedule, Sponsor Declaration of responsibility, declaration concerning the purpose of the data collected. In case of use of placebo and washout, justification of non-maleficence was send. Statement on how the biological material and data, and information collected solely for the purposes specified in the protocol for the study concerned all of which will handle the material and Resolution 251/97 on complementary rules for research with new pharmaceutical products, medicines, vaccines and diagnostic tests [8].

The evaluated research projects were mainly focused on qualitative research $(22 \%)$, case report (18\%), case serie (18\%), epidemiologic studies (18\%), medical genetics (8\%), trial (8\%), case control (8\%) and others. The protocols status has been approved with an accuracy of $61 \%$ on our first evaluation. The main obstacles regard to informed consent and methodologic aspects (67\%) (Figure 1). Moreover, the process of ethical review in REC/APS did not hold back the large majority of the research. Only one research protocol was refused due to improper use of placebo. The final decision about the protocol should be communicated in Platform Brazil and

Table 1. Research ethic committee APS characteristics and functioning.

\begin{tabular}{cc}
\hline Aspects analysed & Results \\
Meetings/year & 10 (montlhy/4 hour/meeting) \\
Protocols/meeting & 6 - 8 protocols \\
Protocol source & Sarah Hospital \\
Minimum members at meeting & 9 \\
Time to first opinion & 14 - 30 days \\
Time to final opinion & 30 days \\
Protocols evaluated & 164 \\
Protocols approved & 64 \\
Complete protocols & 65 \\
Incomplete protocols & 99 \\
Research participants* & 15.400 \\
Report of adverse effects & 0 \\
\hline
\end{tabular}

*Research participant-individual, an informed and voluntarily, or under the clarification and authorization of his responsible legal agree to be searched. 


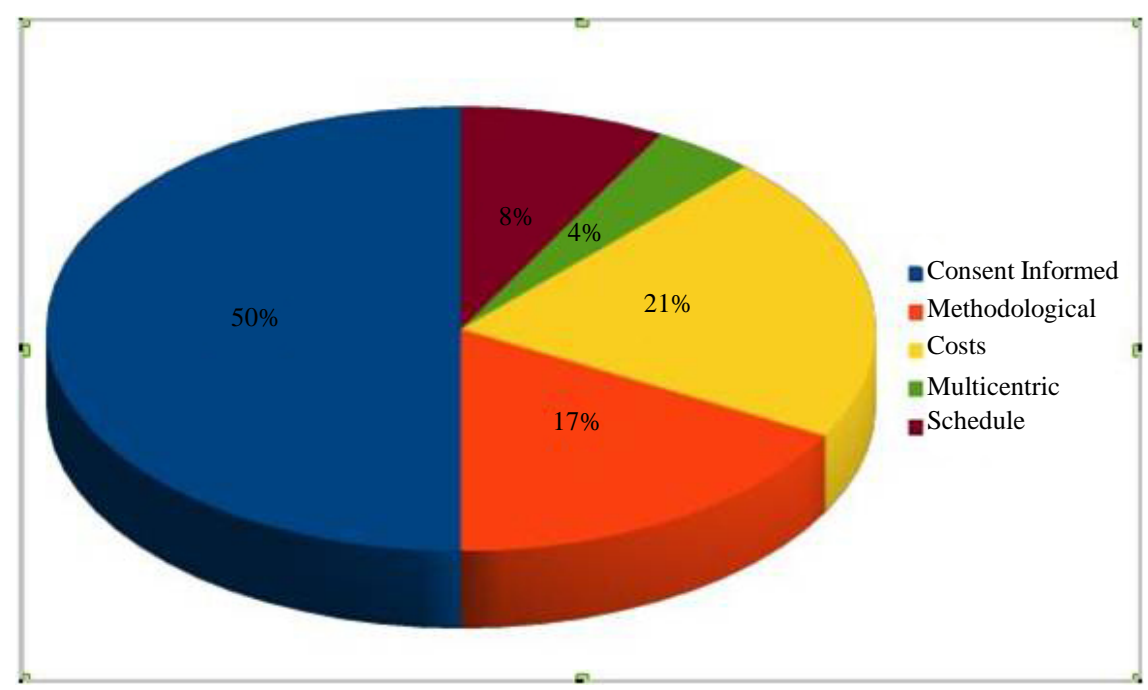

Figure 1. Pendencies distribution of research protocols of REC/APS.

include title, protocol number, researcher, date and approval or refusal decision or recommendations and suggestions for revision and procedure for having the application re-reviewed and signature of the chairperson.

The ethical standard was produced for the Bioethics, National and international normative, law, ethical and, philosophical principles of the justice, autonomy, beneficence and non-maleficence.

\section{Discussion}

This study aimed knowing the experience of the Research Ethical Committee (REC) of the Association of Social Pioneers activities in 2013 [1]. The study was conducted with 2013's data to scrutinize the course of resolving the change of the 466/12 Brazilian Ethical Resolution, which took place the year before the study, and know the impact that applied changes in rules caused to the REC/APS. It was observed as the negative impact of the new resolution 466/12 the amount of 99 incomplete protocols (61.5\%). At 2013, when the new Brazilian Resolution (the 466/12 Resolution's) took effect, we observed that $38.5 \%$ of all projects submitted had the complete and correct documentation.

The year of 2013 was important because it was right after the new resolution, the 466/2012 and the recent electronic system (set up by the Federal Government in 2010), Brazil Platform. However, the database Brazil Platform allowed the possibility of analysis of all data and research protocols from the ethical review system in Brazilian research, but the resolution presented snags of researchers, $61.5 \%$ the protocols did not include the rules of demands.

Furthermore, Porto [9] and collaborators identified the relaxation of control standards research ethics, such as the abolition of the control of the ethical review system on international clinical trials; removal of the need for the adoption of international research by the country of origin; withdrawal of compulsive suspicion of risk by test suspension or injury; use not provided by the data or biological material protocol and remuneration of clinical trials phase of research participants 1 and bioequivalence research.

For trials protocols evaluation, in Brazil we used the Resolution 466/12 on guidelines and rules for research involving human participants that had 28 criteria for approval and Resolution 251/97 on complementary rules for research with new pharmaceutical products, medicines, vaccines and diagnostic tests. In other countries, they adopted a form of ICH-GCP (E6) that had four principles for approval [10], followed by ICH-GCP (E6) and Ministry of Health laws or guidance. Ethical Committee provides a vital independent and public service with the variety of views exposed on the meetings. We need to strike a balance and we must weigh up risks and benefits related to knowledge and its essence to participants. The review should be appropriate to the purpose of the research and all protocol is considered ethical only if its consent is informed.

Although the informed consent process is recognized as an essential requirement in research, actually it is still far from fully realizing the principle of autonomy and respect for persons [11] [12]. In this study, there were failures in the consent informed on $50 \%$ of the protocols. 
Establishing bioethics committees may be a first step for States to create platforms and bodies for ethical debate, analysis and policy development. All research involving human participants should be reviewed by a competent and independent institutional research and ethics committee. We presented the interdisciplinary composition of the APS/REC and its function. Some variation of the point of view is acceptable to inquire the research protocols. However, it's not our job to assess the monetary value of the research, considering that it might be a problem if participants' time and goodwill are misused or vulnerable. For example, how to control the use or misuse of newly acquired biological and medical knowledge and biotechnologies?

According to the National Health Council [5], the Research Ethics Committee (REC) is a volunteer, interdisciplinary and independent collegiate which must exist in institutions conduct research involving humans in Brazil, created to defend interests of the research subjects in their integrity and dignity and to contribute to the development of research within ethical standards. The REC mission is to safeguard the rights and dignity of research subjects. Moreover, REC contributes to the quality of research and for studying the role of discussion in institutional development and social development of the community. It contributes to the enhancement of the researcher who receives recognition that its proposal is ethically appropriate.

At the present time, we need to develop a critical frame of mind and a system of values that prepare us to judge each new research. Here, it is also important to point out that the committee members have been elected to establish the Association of Social Pioneers (APS), located in the Sarah Rehabilitation's Hospital Committee. Despite the implementation of Resolution 466/12 and international regulatory standards, there still are some ethical issues, especially in regards of the methodologic aspects, use of placebo, informed consent and the participation of people under vulnerability in developing countries. We need continuous training and update members. However, the distance of contact between Regional Committees and National Commission of Ethics in Research is a difficulty faced by the REC/APS. Other problems presented are related to Brazil-based data platform and difficulty in monitoring the progress of research. Furthermore, Research Ethical Committees are important on refining research participant protection, adding legitimacy to the research, improving the quality of an intervention being investigated and it can even help mitigate harm [13].

\section{Conclusions}

This article assesses the purpose, composition and functions of the REC/APS and identifies incomplete protocols and pending issues among research protocols presented at 2013. Attention to the normative 466/12 and researcher training could make a difference. However, it is also important to consider the participation of committee members in the preparation of resolutions. Moreover, it is worth mentioning the importance of training committee members in bioethics, appropriate expertise and representation, qualified chair, members, separation of conflict interests from ethics review function, and knowing what the researchers and committee members think about the normative.

Despite the purpose, composition and function of the APS Research Ethical Committee, many hurdles were encountered in its formation, considering monitoring the progress of the research, with the 466/12, national and international ethical and others issues.

The ethical committee does a vital public service with the variety of the specialized views on the meeting. We need to strike a balance and we must weigh up risks and benefits related to knowledge, in its essence, to research's participant and its relevant social participation.

\section{References}

[1] Codigo de Nuremberg, Nuremberg Military Tribunals (1947) The Nuremberg Code. Government Printing Office, Washington DC. http://ohsr.od.nih.gov/guidelines/nuremberg.html

[2] Declaração de Helsinki, World Medical Association (2008) Declaration of Helsinki. WMA, Washington DC.

[3] Declaração Universal Sobre Bioetica e Direitos Humanos. http://unesdoc.unesco.org/images/0014/001461/146180por.pdf

[4] Constituição Brasileira. http://www.senado.gov.br/atividade/const/con1988/CON1988_15.09.2015/ind.asp

[5] Brasil. Conselho Nacional de Saúde, Ministério da Saúde. http://conselho.saude.gov.br/

[6] Brasil. Plataforma Brasil. www.aplicação.saude.gov.br/plataformabrasil/login.jsf

[7] Brasil. Rede Sarah de Hospitais. http://www.sarah.br/ 
[8] Brasil. Resolução 466/12. http://conselho.saude.gov.br/resolucoes/2012/Reso466.pdf

[9] Brasil. O Sistema CEP/CONEP. http://conselho.saude.gov.br/docs/doc ref eticapesq/cadernos\%20conep\%207.pdf

[10] Dora, P., Thiago, C. and Martins, G.Z. (2013) Resolução CNS 466/12:uma crítica necessária. CFM, Brasilia.

[11] Cox, A.C., Fallowfield, L.J. and Jenkins, V.A. (2006) Communication and Informed Consent in Phase 1 Trials: A Review of the Literature. Supportive Care in Cancer, 14, 303-309. http://dx.doi.org/10.1007/s00520-005-0916-2

[12] Bhutta, Z.A. (2004) Beyond Informed Consent. Bull World Health Organ, 82, 771-777.

[13] Goodyear-Smith, F., Jackson, C. and Greenhalgh, T. (2015) Co-Design and Implementation Research: Challenges and Solutions for Ethics Committees. BMC Med Ethics, 16, 78. http://dx.doi.org/10.1186/s12910-015-0072-2 